\title{
An Interpretation of the Chinese American Novel "Been There, Done That" from the Perspective of Initiation Story
}

\author{
Sha Zhu \\ Huaiyin Institute of Technology, Huai'an, Jiangsu Province, China
}

\begin{abstract}
Growth has always been a long, long journey, for everyone. But for one special group, the emigrants, they experience "the journey to the west" and we can have a deeper understanding of their growth by reading relevant books that have a vivid description of their life. Been There, Done That is an autobiographical initiation novel that is written by a young girl Katharine Wang who emigrated to the U.S.A with her parents when she was very young. This novel presents us the rich and colorful high school life of three young emigrants and their friends. These young emigrants were confronted with two diverse cultures, which made their growth tinted with unique characteristics that were quite different from those settled in native soil. The paper aims at analyzing the growth of these young emigrants through three different perspectives, that is, cognitive journey of colorful activities, emotional journey of kinship, friendship and relationship and spirtual journey of ethnic identity. A probe into their distinct cross-cultural growth will not only be conducive to the growth of countless emigrants, but also beneficial to all the teenagers' growth on the whole.
\end{abstract}

Index Terms - growth, Been There, Done That, initiation story

\section{INTRODUCTION}

We all encounter growth in different stages of our life. The growth of a person is to pass through numerous bumpy roads, to suffer traumas of either the soul or the body, and to accumulate experience and knowledge. Every one of us experiences growth in almost every stage of our life. Adolescence, especially, is a period when we stand a greater chance to taste the mixed feelings of growth. Different from us, there is a group of people who immigrate to another country to experience distinct growth far away from their mother land. Settling in our own country, we have few opportunities to get to know their private life and experiences. Nevertheless, a novel Been There, Done That, which is an autobiographical initiation novel written by a young girl, Katharine Wang who moved from China to America with her parents when she was three and a half, furnishes us with insight into the growth experiences of emigrants and the ups and downs of their inner world.

The novel mainly records the high school life of Katharine Wang, which is riddled with joy and tears, showing us the real life of three young Chinese Americans, Katharine Wang, Sunny Zhang and Christopher Dong. They also meet many friends like Erin, Camden and Shawn. Katharine Wang is a quiet and optimistic girl who has a keen interest in reading and writing. Born in Shanghai, Sunny moved to the U.S.A when she entered the fourth grade. As the best friend of Katharine Wang, she is a cheerful and attractive girl. Christopher Dong is an American Born Chinese who gets outstanding grades in school and wants to escape from the control of his parents because of strict parental discipline.

\section{THE INITIATION STORY}

The term "Initiation" comes from the field of anthropology, which mostly refers to the experiences of teenagers get through with the result of gaining knowledge, ability and confidence which helps to independently cope with the future life. (Marcus, 1969). It originates in Germany and was named "Bildungsroman".

In terms of Initiation novel, many researches have been done concerning the topic of growth. Rui and Liu (2005) point out the common pattern of initiation novel, that is, the awful life forces the protagonist to run away and in the end, the protagonist grows up because of the hardship and setbacks he or she suffers. For instance, the novel Adventures of Huckleberry Finn shows the growth of Huckleberry Finn through his experiences and conflicts (Deng, 2010). The tribulation shapes a more confident and mature Huckleberry Finn. What's more, Cao (2014) also analyzes the growth of Margaret in accordance with the pattern. Running away from home, the innocent Margaret recognized her self-identity by experiencing many difficulties.

This Chinese Americans in the novel Been There, Done That, are confronted with two different cultures, so they face one important issue, that is, ethnic identity. Lots of researches are relevant to the theme. In Characteristics of the Ethnic Identity of the Second-Generation Chinese American -In Relevance to That of the First Generation, Hu(2008) dwells on an important ethnic identity orientation: bicultural identity. Furthermore, Wang (2014) indicates that Chinese Americans are forced to explore their individual identity because of the collision of two different cultures. Other 
scholars like Tang (2012), Yuan and Zheng (2009) lay their fingers on the confusion of the new generation Chinese American.

Different from traditional initiation novels that lay emphasis on the growth of the protagonist through his suffering and epiphany, the novel Been There, Done That dwells on daily problems in the process of these young immigrants' growth, including family relationships, peer relationships and relation between the two genders. Moreover, the novel also touches on ethnic identity. Hence, based on the content of the novel, the growth of these young emigrants in immigration will be analyzed in three different perspectives, that is, colorful activities, relationships and ethnic identity.

\section{The Growth Journey in BeEN There, Done THaT}

\section{A. Cognitive Journey of Colorful Activities}

Puberty is the most memorable period of time when we acquire much of the knowledge and skills at school where sundry activities are held to expand our horizon. Katharine Wang spent her four-year high school at Susan Jones Preparatory Schools of California in which she engaged in many activities that shape her character and promote her growth.

1. Growth in the Fantastic School Activities

At Susan Jones Preparatory Schools, there are various activities, like talent shows, proms and candlelight ceremony. These scenes and feelings at school are the snapshots of her four-year high school life, such as her uneasiness in the course of the interview, her joys after becoming class president, her awkwardness when signing the enrollment book. It is at this school that Katharine Wang experienced colorful activities and acquainted herself with many friends. These activities, which enrich the high school life of Katharine Wang and provide her with a platform to better herself and go farther in the path of growth are specifically selected and will be elaborated respectively in the following part.

It is difficult for American students to attend a good high school. Before hearing the good news that she was admitted into Susan Jones Preparatory Schools, Katharine Wang went through a grilling interview from which she drew lessons. The interviewer Ms. Miller asked Katharine Wang several questions related with her future targets, appetites and favorite lessons. When asked the favorite classes, instead of saying the top ones like math or science as her father told her, she said that she likes history entirely from instinct.

Katharine Wang learned from the interview that the best way to make a good impression on interviewers is to be yourself. "One thing I have learned from interviews is that the first inclination is to act like the perfect student: I love everything and want to do everything. That is appreciated in many cases, but sometimes if you are not as passionate... the best way is to be yourself' (Wang, 2004, p.7). Katharine Wang understood that in the interview, the interviewers are insightful and witty. Hence, it's better to show true self. Therefore, Ms. Miller was pleased with her performance. In contrast to Katharine Wang, many Chinese students are apt to act like the top students and even recite the so-called standard answer to please the interviewers. During the interview, Katharine Wang had her own judgments and refused to be absolutely obedient to her parents' requirements. This is a mark of her growth.

After the grilling interview, Katharine Wang started her high school life. As a freshman, she placed posters up over the school with her friends Sunny, Erin and Kiara in order to run for freshmen class president. However, unfortunately, a week before the election, all the posters they put up disappeared. But other candidates' posters remain untouched. Feeling frustrated, she still tried to make more posters. Later, she knew that Jessica, a good friend of her rival Alison, another candidate, pulled down the posters. Although it sounded like some dirty conspiracies, Katharine Wang didn't give up. She prepared for the speech the rest of the week and her friend Kiara tried to help her win the support of the boarders. After the nervous speech time, she successfully became the freshmen class president.

From the election, Katharine Wang learned that one should not doubt the potential he or she possesses. Although Katharine Wang is a plain Jane with unattractive appearance, she unexpectedly prevails over her opponents. Katharine Wang also learned that we should deal with failure rationally and face success calmly. "I have my share of failures, but I have also known what winning tastes like, too. And I think that in this world, winning and losing go hand in hand. Just like the old saying: how do you know happiness if you have never had pain" (Wang, 2004, p. 21). It's true that achieving a goal is difficult, but giving up first is even worse. She knew that winning and losing are closely bound up, so do happiness and pain. Just like the old saying: Pleasure comes through toil. Later, her second attempt to run for sophomore class president turned out to be a failure, but she still embraced it and faced it with a smile. Katharine Wang's understanding of potential, failure and success helps her grow up.

Life is saturated with possibility, failure and success, and everyone is likely to make mistakes. Katharine Wang's another experience enables her to know more about mistakes. At Susan Jones Preparatory Schools, teachers give their Chapel talks about life lessons, moralities and experiences two times a week. When Katharine Wang was a freshman, she and other students were asked to step up to the altar, sign the enrollment book when their names were called. When Ms. Moore called Katharine Wang's name, Katharine Wang made her way toward the altar and wrote down her name neatly on the old book. Nevertheless, after writing the name, she found herself spelling her name wrong. A wave of panic went up through her throat; she tried to correct the error by crossing out her name and writing it again. At the same time, she was afraid to see the mocking facial expressions of all the students. Surprisingly, her friend Sunny made a similar embarrassing mistake. However, they looked at each other and grinned. After that, Katharine Wang rapidly realized that she should not pay too much attention to such mistakes, which often upset the youngsters. 
In adolescence, most teenagers place a very high value on minor mistakes or have faults magnified that they may feel embarrassed or distressed about trivial matters. Different from those teenagers, Katharine Wang tried to act more like an adult and viewed her mistakes more rationally. She deemed that such mistakes like spelling her name wrong would not prove that she was a stupid girl. "So if you one day slam into a clear, glass window or hit a pole or even use mouth wash as shampoo, just think of yourself as 100\% human "(Wang, 2004, p. 43). She thought that everyone would do silly things once in a while. Don't doubt ourselves as smart people just because of some minor mistakes. Everyone is allowed to make mistakes that are brainless or natural and just consider ourselves as human_beings.

Katharine participated in various activities that promoted her growth. The interview and her understanding of potential, success, failure and mistakes show us a more mature girl who is adept at experiencing life.

2. Learning in the Meaningful Out-of-school Activities

In addition to fantastic school activities, Susan Jones Preparatory Schools also organizes a myriad of out-of-school activities, such as trips to Museum of Tolerance and to Youth Wellness Center, which also facilitate the growth of Katharine Wang.

The sophomore class took a trip to the Museum of Tolerance so as to understand better various historical events. The exhibition was full of artworks and they stared at paintings for a long time. Ms. Cohen, associates of the Museum of Tolerance, told them a story about her life. She was branded with a code on her arm in that she used to be a prisoner of the concentration camp. When Katharine Wang saw the bar code, she thought it was the saddest sight she has ever seen. The heartbreaking story reminded her of the Nanjing massacre, which shows outrageous behavior of Japanese Imperial army. On their way back, Katharine Wang was still haunted by powerful images seen from the Museum of Tolerance, like a soldier shooting at a mother with baby in her arms.

Some Chinese students would take it for granted that various trips are just a relaxing time for playing and eating snacks. But Katharine Wang was serious about the trip and made the best of the chance to have insight into different historical events. She even had a deep understanding of humanity, tolerance and pluralism. "People are different, but they are just good as you are. I sure felt that I appreciated life more and I should reach out and help people more. It is the way of life, isn't it?" (Wang, 2004, p. 125) She found that after the trip to the museum, she was more sympathetic and sensitive about the feelings of other people. She realized that helping more people was the way of living, and that made life meaningful. She also thought that people are different, but they are equal regardless of race, color, or nationality.

Another trip to the Youth Wellness Center enabled her to learn more. The Youth Wellness Center aims at helping children with their homework, study and outdoor activities after school. Katharine Wang joined the service program to tutor kids and communicate with the elderly. The program opened her eyes to the real world and she felt that she had done meaningful things that made a difference in other people's lives and touched their hearts.

China's domestic education system lays stress on grades, different from most Chinese students who immerse themselves in studies, Katharine Wang did volunteer work with pleasure. The trip to the Youth Wellness Center enabled her to learn important lessons about richness and love.

Katharine Wang tutored a child named Angelica who came from a low-income family. The girl asked her a "powerful" question about richness, that is, what it was like to be rich. Katharine Wang didn't give her a general answer about "richness" because she considered that the girl came from a family with five other children and her parents' wage even cannot live up to the expectation of making a living, so Katharine Wang didn't want to break Angelica's heart, which showed that she really learned to be considerate of others.

From the elderly people, she learned another lesson about love. She met a retired Italian woman named Rose, who was ninety-seven years old. Katharine Wang had a conversation with Rose. Rose told her the love experience and some information about family members. Rose's words penetrated Katharine Wang's heart and stayed with her for a long time. She understood that everyone should not take for granted the life of a loved one. We must cherish each moment spent with the loved and savor the time because one day, what left with us is nothing but memory. Katharine Wang's conversation with the child made her understand the real meaning of reaching out to other people with a sincere caring and her conversation with the old made her understand the actual meaning of love and cherishing.

All the out-of-school activities Katharine Wang attended provide her with opportunities to deepen her thoughts, to reach out more empathy and concern for some seemly "abstract" concepts.

\section{B Emotional Journey of Kinship, Friendship and Love}

Katharine Wang not only learned a lot from colorful activities, but also grew up in the love from her family members and intimate friends. Her parents exerted great influence on her growth as they provided her with guidance. Her intimate friends played a great role in her emotional life as they helped her out of the plight. Katharine Wang, Sunny and Christopher even encountered their puppy love at school, which facilitated their growth to a large extent.

1 Instruction of Family

Katharine Wang' parents, deeply rooted in Chinese traditional culture, were strict with her. They even made "ten commandments" which in fact were ten rules to restrict her behaviors. Just like so many Chinese fathers, one of her father's "hobbies" was to give a lecture about everything, such as the dangers of love in school, the importance of time allocation. Her parents' guidance played a pivotal role in her growth.

In cross cultural environment, Katharine Wang still borne her parents' words in mind and carried it out earnestly 
when it made sense. For example, Katharine Wang went out to study with her friends to prepare for the semester exam because she believed that study sessions were a more effective way of studying. But that day was fruitless as she spent several hours to argue with Camden about relationships. She was remorseful and thought that she should have listened to her parents and stayed at home to concentrate on test preparations. Afterwards, her semester final exam scores turned out to be a failure, so she decided not to repeat the same mistake again in her next semester because her parents told her that she was doing everything for herself. She tried to be responsible for herself and never made empty promises. Moreover, when Katharine Wang tried to run for the president in the second year, she was faced with strong opponents and the air of competition filled in each classroom and meeting. But one thing her parents taught her was: never give up. With these words in mind, she made up her mind to run again because if a person never tries, he is destined to be a loser. Though the speech was better than the first year, Katharine didn't win the class president again. However, she was optimistic and positive after a wave of overwhelming grief. Katharine Wang didn't like to lose, but she knew that losing is a kind of bump in the road of life. She believed that failing comes before succeeding and it's a valuable opportunity to learn how to cope with failures, just as the old famous Chinese proverb goes: Failure is the mother of success.

As an emigrant settled abroad for more than fourteen years, she could embrace her parents' notions that were much like the opinions of traditional Chinese parents, such as doing everything for yourself instead of for your parents and never give up. But in China, for many teenagers at this age, their parents' words seemed to go in one ear and out the other even if these words are reasonable. Katharine Wang could make her parents' guidance to lead her behaviors, showing maturity for her age.

With the help of family guidance, Katharine Wang established a correct outlook on life and values, which contributes a lot to her growth.

2 Nourishment of Friendship

Katharine Wang learned and grew not only from her family, but also from her friends who constantly offered help and lighted up her world when she was in a gloomy mood. She acquainted herself with many friends with diverse characteristics and also tried her utmost to support her friends.

Sunny was one of Katharine Wang's best friends because they share similar background, choice of music and sense of humor. They spent the four-year high school together and form strong partnerships. They played with each other, helped with each other and shared secrets with each other. For example, Sunny help Katharine Wang run for the freshmen class president by putting up posters and offering encouragements. Katharine Wang helped Sunny deal with love affairs and gave suggestions. For instance, they talked about Shawn in their sleeping bag and when Sunny didn't know what to do with her relationship with Shawn, Katharine Wang suggested that she should take it as it comes. "In terms of relationship, sometimes the best thing to do is let the Three Fates decide. You'll be just lying to yourself if you say you don't. And to deny yourself is to hurt yourself." (Wang, 2004, p.133) Katharine Wang's involvement in Sunny's love trouble helped her become more mature and rational.

Their friendship taught them how to deal with interpersonal relationships and enabled them to have a deeper understanding towards friendship. Katharine Wang believed that it's a kind of comfort to know that we have a shoulder to lean on no matter who we are or where we are. We are likely to receive the help of others or might be the one reaching out to help. She regarded friendship as her second family that should never be underestimated as friendship kept her awake and energetic. Sunny also realized that friendship is very important and she helped Katharine Wang with daily problems and asked her for advice.

Except Sunny, Katharine Wang also met another friend Victoria who was an odd girl with a fascination for witchcraft. The first time they met, Victoria's pale complexion and all black outfit made her look like a Gothic, which resulted in derogatory talks from some students. Different from most students who were prejudiced and unwilling to invite her over, Katharine Wang gave a warm welcome to Victoria and helped her with hiking. Influenced by traditional Chinese culture instilled in her mind through her parents' guidance, Katharine Wang holds the opinion that we should not judge a person by outer appearances or before actually getting to know her or him. As the saying goes, don't judge a book by its cover. Lots of classmates missed out their friendship with Victoria just because they could not step out of the prejudice and to really know a person. As an emigrant who had the opportunity to contact students from all over the world, Katharine Wang also believed that a mixture of people makes the world turn and makes our life taste better.

In the nourishment of friendship, Katharine Wang had a wiser thought of making friends and getting along with friends, which took her a mile on the road of growth.

3 First Taste of Love

It is universally acknowledged that love is a requisite part of our life from which we draw valuable lessons. These young emigrants not only influenced a lot by their family and friends, but also by their lovers although their love may be green or just puppy love of one sort or another.

Katharine Wang's relationship with Camden looked more like a kind of special love. The first time Katharine Wang met Camden, she felt awkward and even didn't know what to say. In her opinion, Camden was friendly, cute, and a good-looking distraction. She even felt uneasy at his side and tried to shift a little away. Her uneasiness and awkwardness toward Camden showed her green love, of which she may not be consciously aware. She danced with Camden like stick figures and kept a safe distance because she accepts her father's advice that students should concentrate on study and high school relationship is doomed to be an unhappy ending. Although Katharine Wang tried 
to persuade herself to leave romance, she was still concerned with everything with Camden. For example, she never felt so scared in her life when she saw Camden go unconscious and almost drown in the swimming pool but can do nothing to help. The incident flashed through her head all summer, showing her concern for Camden. What's more, when she knew Camden's pains behind the smile, she tried to relieve his pain and talked with him. After knowing the sad story of Camden's mother, Katharine Wang persuaded him out of taking his own life. She (2004) said: "Life comes by once, Cam. Don't mess it up like your mother did. She didn't value the blessings of each moment; she didn't value what she had. Instead, she died of guilt for not appreciating these things. She wouldn't have wanted you to do the same thing."(p.183) Her words took effect and Camden realized that life was more important than something happened and what he needed to do was to let go of his past and looked into the future. Apparently, Katharine Wang and Camden liked each other, but both of them hesitated to say their feelings. Katharine Wang's relationship with Camden carried her further on the road of growth as she witnessed Camden's pain and knew how to deal with pains in a proper way. "Real growth is always accompanied with pain, which we have to face. Only in this way can we realize the transformation of growth."(Mo, 2016, p.188) Pain is very important to a person's growth as it can make a person become tougher. Katharine Wang's involvement in Camden's pain taught her to face up to pain and never run away from it. Actually, until the end of the novel, they are still very good friends, but both of them learn to deal with the difficulties in the life together, which helps them develop better in the future.

Different from Katharine Wang and Camden, the love between Sunny and Shawn was bolder and more passionate. Shawn used to be a naughty boy who liked playing tricks on others. Teachers had the worst time because of him and partly owing to his father's powerful background, he transferred from school to school. Sunny and Shawn met each other in physics class and later Shawn became Sunny's tutor to help her with academic improvements. At first, Sunny was unsure whether she loved Shawn or not but Shawn kissed her when one night she tried to lurk out of the dorm to protect him against school punishment. Shawn loved Sunny because she was a good girl, but he wanted her to leave him because he thought Sunny should not make friends with a bastard like himself. So, he used that kiss to push her away. However, Sunny gradually found that she was half in love with him. When Shawn apologized to her for the kiss at that night, Sunny helped him find who he really was. In order to make sure Sunny loved him, Shawn pretended to leave the school by flight. When Sunny knew the news, she hurried barefooted to find Shawn regardless of pain and tumbling. Fortunately, through the departure, they both realized that they love each other. There is more to them than what meets the eye. In few months, Sunny learned more about herself and opened up more. Sunny used to immersed herself in learning. She would be depressed if she gets a B on test. After she met Shawn, she opened up her heart to Shawn. She tried to protect Shawn from school punishment. They even went to the same summer program. When asked whether it was possible to find love in high school, the better she knew Shawn, she was more sure about the answer: Yes. The love experience made her become a better self.

Except Katharine Wang and Sunny, Christopher also experienced love in a distinctive way. When Christopher and Erin first met, they made a deal for their mutual benefits that if Erin helps Christopher get around the school, he will help her every day with soccer tricks. Because of the deal, they were chained to each other for a month. Christopher liked Erin a lot because the young American girl was appealing considering her multiple personalities like arrogance, spontaneousness and hot-headedness. Erin didn't realize that she loved Christopher until when another boy Jonathan tried to kiss her, her mind was full of scenes with Christopher like his smile, his encouragement and his help. Christopher wanted to get out of control from his parents and get rid of the planned fate that study hard to go to a good Ivy University, take over the company of his father and marry a girl who lives up to his parents' expectations. He had his own plans for his future and his dream was to become a professor. His parents paved future for him, but his sole aspiration was to be himself. Erin was a girl who helped him with self-discovery and that was the reason why he liked her so much. The love experience made him know himself better and made him become more courageous.

Love has magical power, it helps these young emigrants find the true self and walk out of the adversity. Love contributes a lot to their growth because it teaches them how to care about others, help others and perfect themselves.

\section{Spirtual Journey of Ethnic Identity}

As a Chinese American, Katharine Wang moved to America at the age of three and a half. Katharine Wang was embedded in two different cultures as on the one hand her parents were deeply influenced by traditional Chinese culture and on the other side, she received American education at an early age. Like most emigrants, she also encountered a big problem, that is, the problem of ethnic identity.

1. Complex Feelings Towards Ethnic Identity

Kids of Chinese immigrants are often called "banana" because they are yellow on the outside, but they are white inside. Some new people can be Americanized in a short time. They seem to be whitewashed and consider themselves white. Katharine Wang wished that she could be like them and considered herself American. But the truth was that she wrestled with two ideals. "I wanted to be American, but there was an invisible thread that kept pulling me back. I was beginning to listen more to Chinese pop music and even conforming to the FOPly dress" (Wang, 2004, p.27) Her thought showed that she was confused with her ethnic identity. Although she tried to behave like an American, she actually felt that she behaved like a Chinese sometimes. Her lack of self-confidence in ethnic identity made her feel that she was inferior to those Americans. For instance, the first time camping out with her classmates, Katharine Wang saw her new friends clustered by the bonfire, she buttoned up her mouth because she thought that she was a plain-looking 
Chinese while her new friends were blonde white girls. But gradually, she changed her ideas and was confident of her ethnic identity.

2 Firm Blief Towards Ethnic Identity

As we all know, America is a melting pot that encompasses all diverse cultures and it was founded on the principles of equality and freedom. America is also a country that underscores the individualism which emphasizes that everyone is his own master and everyone should search for his own values. Katharine Wang got an education in the America for more than ten years, influenced by American culture, she realized that a true American stands for diversity and stands proud against adversity. With that definition, she was no longer puzzled for her ethnic identity. "I'm Chinese American. For that, I think I have the best of both worlds. Being Chinese American has a whole new level of meaning to itself" (Wang, 2004, p. 186). She realized that she had a bi-culture identity that can be comfortably adjusted according to different needs or situations. Her trip to the Museum of Tolerance enabled her to have a better understanding of pluralism. She believed that everyone was equal no matter which race he or she belonged to. Her belief was similar to the idea of Homi K Bhabha, a representative figure of contemporary post-colonial studies. He introduces the concept of "hybridity", which lays emphasis on multiculturalism and he believes that new cultural identities can be created through the integration of the colony's own cultural identity and the colonizer's cultural identity (Wang, 2002).

Katharine Wang's belief of ethnic identity helped her gain more confidence and became more successful. She can switch from one culture to another and find the most comfortable position between two diverse cultures.

\section{CONCLUSION}

In the novel Been There, Done That, three young emigrants achieved a lot from their high school life and reaped love and friendship. Going through various setbacks and trials, they became more mature and will weather other storms of life in the future.

By participating in many activities inside and outside of the school, Katharine Wang realizes the importance of showing true self, bringing potential into full play and looking squarely at success and failure. She also understands the meaning of helping others and cherishes love and people around her. Especially, in the nourishment of love and care from her family, friends and lover, Katharine Wang learns to embrace her parents' ideas and spares no effort to support and help her friends and loves. The friendship between Katharine Wang and Sunny helps Sunny to deal with interpersonal relationship better. Sunny's love with Shawn enables her learn more about herself and open up more. The love experience between Christopher and Erin help Christopher knows himself better and tries to hold on to his dream. He becomes more courageous and tries to follow his own heart. During the four years, Katharine Wang attains intelligence, ability and acuteness as she grows up. More importantly, she holds a clearer view towards ethnic identity and realizes that as a Chinese American, she has the best of both cultures. Their growth helps broaden their horizons and the world gets bigger in front of them. The life lessons they get during the adolescent years will definitely benefit them a lot.

These youngsters' growth will also be beneficial to all the other emigrants and even all the adolescents in the world.

\section{REFERENCES}

[1] Cao, Huan. (2015). An Interpretation of I Know Why the Caged Bird Sings from the Perspective of Initiation Story. Master thesis, Qiqihar University.

[2] Deng, He. (2010). An Analysis of Adventures of Huckleberry Finn from the Perspective of Personal Growth. Literature, 6,77-78.

[3] Hu, Yiying. (2008). Characteristics of the Ethnic Identity of the Second-Generation Chinese Americans-In Relevance to That of the First Generation. Master thesis, China Foreign Affairs University.

[4] Mo, Xiaoya. (2016). An Analysis of Amir in The Kite Runner from the Perspective of Personal Growth. Overseas English, 21, 187-188.

[5] Mordecai, Marcus. (1969). What Is an Initiation Story. In Coyle William (Eds.). The Young Man in American Literature:The Initiation Theme. New York:The Odyssey Press, 32.

[6] Rui, Yuping \& Liu, Chunhui. (2005). A Study of American Literature from a New Perspective of Personal Growth. Journal of Ningbo University (Liberal Arts Edition), 1, 1-5.

[7] Tang, Shuyan. (2012). An Analysis of Identity and Voice in Chinese American Literature. Master thesis, Nanchang University.

[8] Wang, Chaojie. (2014). A Study of Amy Tan's The Joy Luck Club from the Perspective of Cultural Identity. Journal of Jining University, 4, 43-46.

[9] Wang, Katharine. (2004). Been There, Done That. Beijing: Foreign Language and Research Press.

[10] Wang, Ning. (2002). A Review of Homi Baba's Postcolonial Theory. Foreign Literature, 6, 48-55.

[11] Yu, Ting. (2013). An Analysis of The Kite Runner From the Perspective of Initiation Story. Master thesis, Liaoning University.

[12] Yuan, Suhua \& Zheng Zhuorui. (2009). On the Perplexity of New Generation Cultural Identity of European and American Chinese. Hubei Social Sciences, 8, 109-111.

Sha Zhu is currently a lecturer in the School of Foreign Languages, Huaiyin Institute of Technology, Huai' an, Jiangsu Province of China. Her research interests include intercultural communication and youth literature. 